\title{
Passive Smoking is Associated with Risk of Early Onset of Cardiac Dysfunction
}

\section{${ }^{1}$ Azza M. Abul-Fadl AM*, ${ }^{2}$ Mohamed Darwish, ${ }^{3}$ Nehad Taha Bishr, ${ }^{4}$ Eman Gamal Amer, ${ }^{5}$ Ayoub Al- Jawaldeh}

\author{
${ }^{1}$ Emeritus Professor of pediatrics, Benha faculty of medicine, Egypt \\ ${ }^{2}$ Lecturer of Cardiology, Benha faculty of medicine, Egypt \\ ${ }^{3,4}$ Lecturer of Pediatrics, Benha faculty of medicine, Egypt \\ ${ }^{5}$ Lecturer in Nutrition sciences, University of Vienna, Austria
}

\begin{abstract}
Background: Second hand smoke (SHS) exposes infants and young children to many short and long term hazards. In adults PS was found to result in left sided diastolic dysfunction.

Aim: To identify changes in the structure and function of the right side of the heart that can be influenced by exposure of infants to SHS.

Methods: Echocardiographic evaluation of the right side of the heart was carried out for 75 infants aged 3 to 12 months of age; 39 were formula milk fed (FF) from birth and an age matched control of 36 breastfed (BF) infants. A sub-analysis was done for each group in relation to exposure to PS. Measurements included Tricuspid annular plane excursion (TAPSE) and S' wave for peak systolic annular velocity for right systolic function, E wave (early passive ventricular filling) and E/A ratio, tissue Doppler imaging (TDI) for $E^{\prime}$ and $A^{\prime}$ and $E / E^{\prime}$ prime ratio for assessing ventricular filling pressure for diastolic dysfunction.
\end{abstract}

Findings: TDI in FF showed significantly higher values for $\mathrm{E}$ prime and $\mathrm{E} / \mathrm{E}$ ' ratio in infants not exposed to SHS vs. those exposed to SHS $(12.5 \pm 0.96 \mathrm{~cm}$ vs. $11.1 \pm 1.1 \mathrm{~cm}$ at $\mathrm{P}=0.000)$ and $\mathrm{E} / \mathrm{E}^{\prime}(6.65 \pm 0.9$ vs. $7.7 \pm 0.9$ at $\mathrm{P}=0.003$ ) respectively. There were no significant differences in systolic function (TAPSE) and $\mathrm{S}$ ' wave. However RV diameter was significantly higher in those exposed to SHS $(1.3 \pm 0.09 \mathrm{~cm})$ vs. no exposure $(1.2 \pm 0.07 \mathrm{~cm})$ at $\mathrm{P}<0.05$. In the $\mathrm{BF}$ there were no significant differences in all dimensions examined for SHS exposures and no exposures.

Conclusions: SHS in FF infants are at risk of right sided diastolic dysfunction while early breastfeeding seems to protect the heart from the hazards of SHS.

Keywords: Second hand smoke, infancy, echocardiography, right ventricular systolic function, right ventricular diastolic function, early feeding.

\section{Introduction}

Active smoking is known to be implicated in the causation of cardiovascular disease (CVD) morbidity and mortality. Over the past four decades there has been increasing research showing evidence that exposure to smoke either through direct contact with a smoker i.e. second hand smoke (SHS) or indirectly through exposure to furniture or environment previously exposed to smoke i.e. tertiary smoke (TS). PS causes increased prevalence of chronic diseases and increases prevalence of death by $20 \%$ (Rushton, 2004).

SHS has more devastating effects on neonates and infants because of their partially developed and compromised cardiovascular and endocrine and immune systems, especially that SHS contains carcinogenic substances as arsenic which is implicated in the causation of CVD (Miller et al., 2005). A systemic review on the effects of SHS on the CVD identified a total of 42 relevant articles (i.e. 30 reviews and 12 observational). Results revealed that passive smoking may be implicated in deteriorating cardiovascular 
status in children in terms of unfavourable high density lipoprotein levels and deteriorated vascular function (Metsios et al., 2010).

Studies regarding echo changes after exposure to SHS are few. One study in Turkey showed that acute exposure to passive smoking was found to impair left ventricular function (LVF) in healthy volunteers. They reported that transmitral $\mathrm{E}$ wave and pulmonary venous $\mathrm{D}$ wave and $\mathrm{E} / \mathrm{A}$ ratio decreased reflecting left diastolic dysfunction (Dogan et al., 2011). Echocardiographic evaluation of LVF is reliably assessed through M-mode, pulsed wave Doppler and Tissue Doppler and 3D because of the uniform shape of the LV. However the because of the abnormal shape of the right ventricle, parameters used to assess RVF are different.

The size of the cardiac chambers increase progressively with growth-reaching half the adult size by 5 years and $90 \%$ of adult size by 12 years of age. The growth of these structures may be influenced by external insults as SHS and may influence the development of CVD in later life. Hence the aim of thois study was to examine the echocardiographic changes in right side of the heart in infants exposed to SHS in the first year of life.

\section{Subjects and Methods}

Study design and population: This is a cross sectional case-control study that examined cardiac functions and dimensions of infants aged 3-12 months who were exposed to SHS vs. those not exposed to AHS. The study was carried out for 35 infants of either sex (18 males and 17 females). Inclusion criteria were included healthy full term babies from birth until age of one year who were formula feeding from birth. Exclusion criteria were included major congenital anomalies, acute or chronic diseases, babies on medications or exposed to irradiation and congenital heart disease. The children were selected from the outpatient clinic of Benha university Hospital.

Ethical clearance: The study was approved by Ethics Committee of Faculty of Benha University. Confidentiality was taken into consideration by using a reference code number for each child. Verbal informed consents were obtained from parents of all subjects of the study. General and systemic examination for heart and chest were done to exclude any abnormality. When using the reports and investigation of the baby we hide names and addresses and the results of investigation was done in the scientific publishing.

Anthropometry: Anthropometric measurements for weight to the nearest gms and expressed in $\mathrm{kg}$. Supine length was measured to the nearest mm by standard methods ${ }^{(4)}$. Body mass index (BMI) was calculated by weight in $\mathrm{kg}$ divided by length squared in meters.

Echocardiography: Cardiac output (CO), heart rate (HR) and body surface area (BSA) were estimated by standard methods. Echocardiography measurements included right ventricular diameter (RVd mm), Right ventricular out tract diameter (RVOT mm), right ventricular velocity time integral (RV VTI/cm), Tricuspid annular plane excursion (TAPSE), Percent Fractional shortening (\%FS) or \%fractional area change (\%FAC) were measured using methods recommended by the American Society of Echocardiography ${ }^{(5)}$. Right ventricular mass (RV mass) was computed using the formula derived by: (4/5 Pi D1D2L) ${ }^{(6,7)}$. Two-D, Mmode, continuous pulsed wave (PW), color Doppler and tissue Doppler Imaging (TDI) were performed with standard sweeps including subcostal, parasternal, apical and suprasternal views ${ }^{(7)}$. PW Doppler was done for the tricuspid valve (TV) both at the septum and anterior valve to measure the TV flow (E and A wave and E/A ratio. TDI was done at the lateral annular plane of TV to assess $S$ ' wave for peak systolic annular velocity, E' wave for early diastolic and A' wave for late diastolic filling due to atrial contraction phase. Isovolumetinflowric relaxation time and isovolumetric contraction time used to assess myocardial performance indec (MPI) or Tei indiex were also calculated, but because they are very small on the right side, they are used for the left side more.

Statistical analysis: The collected data were tabulated and analyzed using SPSS version 16 software (SPSS Inc, Chicago, ILL Company). Categorical data were presented as number and percentages, Chi square $\left(\chi^{2}\right)$ and Fisher's exact test (FET) were used to analyze them. Quantitative data were tested for normality using Shapiro-Wilks test assuming normality at $\mathrm{P}>0.05$. Normally distributed variables were expressed as mean 
\pm standard deviation and analyzed by Student " $t$ " test for 2 independent groups. Correlations were estimated using Pearson's correlation coefficient. A p-value $\leq 0.05$ was considered significant.

\section{Results}

Table (1) presents the mean and SDS for age, maternal age, educational status, working status, husband age and parity. Passive smoking was prevalent in 48 of the $75(64 \%)$ compared tp $27(36 \%)$. There were no significant differences between the ecological data of both groups $\mathrm{P}>0.05$ except for work status of mother that was significantly higher in mothers who were not exposed to SHS $(\mathrm{P}=0.000)$.

The CO; \%FAC, RV mass, E and E/A ratio were not significantly different between those infants not exposed to SHS and those exposed to SHS as shown in table (2). Also the echocardiographic structural dimensions of the right side of the heart for TAPSE, RVOT and RV VTI were not significantly different between FF exposed to SHS and those not exposed to SHS. However the RV diameter at the base was significantly higher in FF infants exposed to SHS $(1.3 \pm 0.09)$ vs. those not exposed $(1.2 \pm 0.07$ at $\mathrm{P}<0.05)$ respectively as shown in table (3).

Tissue Doppler Imaging (TDI) findings of TV inflow signal at septum are shown in table (4) that compare infants (3-12 months of age) not exposed to SHS vs. those exposed to SHS. There was significant difference between FF infants not exposed to SHS vs. those exposed to SHS regarding E' prime wave $(12.5 \pm 0.96 \mathrm{~cm}$ vs. $11.1 \pm 1.1 \mathrm{~cm}$ at $\mathrm{P}=0.000)$ and $\mathrm{E} / \mathrm{E}^{\prime}(6.65 \pm 0.9$ vs. $7.7 \pm 0.9$ at $\mathrm{P}=0.003)$ respectively. Comparison of $\mathrm{FF}$ infants (3-12 months of age) not exposed to SHS vs. those exposed to SHS showed no significant differences in parameters measured by Tissue Doppler for TV signal at anterior leaflet of TV between infants not exposed to SHS vs. those exposed to SHS at P>0.05 as shown in table (5).

Correlative studies done in the group of FF infants in relation to SHS with the different parameters measured for right ventricular systolic and diastolic function are shown in table (6). Significant correlations were present in relation to exposure to SHS in FF with RV diameter ( $\mathrm{r} 0.3$ at $\mathrm{P}<0.05)$, A wave $(\mathrm{r} 0.5, \mathrm{P}=0.003)$ and $\mathrm{S}$ wave $(\mathrm{r}-0.6, \mathrm{P}=0.000)$. In Table (7) similar statistical analysis showed that there were no significant correlations between echocardiographic parameters and status of SHS among EBF P>0.05.

Table (1): Comparison of mean epidemiological data of all infants under study aged 3-12 months exposed to passive smoking vs. those not exposed to smoke

\begin{tabular}{|l|l|l|l|l|l|}
\hline \multicolumn{2}{|l|}{ Variables } & Range & Mean \pm SDS & F-ratio & P-level of sign \\
\hline \multirow{2}{*}{ Age (75) } & SHS (48) & $3.0-12$ & $7.6 \pm 3.2$ & 0.6 & 0.8 \\
\cline { 2 - 6 } & No SHS (27) & $3.0-12$ & $7.4 \pm 2.7$ & & \\
\hline \multirow{2}{*}{$\begin{array}{l}\text { Mother age } \\
\text { (75) }\end{array}$} & SHS (48) & $21.0-36$ & $27.1 \pm 4.6$ & 0.48 & 0.49 \\
\cline { 2 - 6 } & No SHS (27) & $21.0-34$ & $27.8 \pm 3.8$ & & \\
\hline \multirow{2}{*}{$\begin{array}{l}\text { Mother } \\
\text { work (75) }\end{array}$} & SHS (48) & $0-1$ & $0.1 \pm 0.33$ & 38.8 & $0.0 * *$ \\
\hline \multirow{2}{*}{$\begin{array}{l}\text { Mother } \\
\text { educ (75) }\end{array}$} & No SHS (27) & $0-1$ & $0.7 \pm 0.5$ & & \\
\hline \multirow{2}{*}{$\begin{array}{l}\text { Husband } \\
\text { age (75) }\end{array}$} & SHS (48) & $2.0-3.0$ & $2.7 \pm 0.44$ & 1.05 & 0.31 \\
\hline & SHS (48) & $2.0-3.0$ & $2.8 \pm 0.36$ & & \\
\hline \multirow{2}{*}{ Parity (75) } & No SHS (27) & $24.0-40$ & $29.9 \pm 4.2$ & 0.25 & 0.4 \\
\cline { 2 - 6 } & SHS (48) & $1.0-4.0$ & $1.7 \pm 0.8$ & 0.7 & \\
\hline
\end{tabular}

*Cut off value of significance $P<0.05$. ** Highly significant.

SHS: Passive smoking, BSA: Body surface area in square meters *Cut off level of significance is $\mathrm{P}<0.05$; 
Table (2): Comparison of cardiac output and right ventricular mass, percent fractional change, Pulsed wave Tricuspid valve inflow signal ( $E$ and $E$ to $A$ ratio) in infants aged 3-12 months exposed to passive smoking vs. those not exposed to smoke

\begin{tabular}{|c|c|c|c|c|c|}
\hline \multicolumn{2}{|c|}{$\begin{array}{l}\text { Parameter of RV function and groups } \\
\text { under study (number of cases) }\end{array}$} & \multirow{2}{*}{$\begin{array}{l}\text { Range } \\
3.03-6.3 \\
\end{array}$} & \multirow{2}{*}{$\begin{array}{l}\text { Mean } \\
\text { Deviation }\end{array}$ Std. } & \multirow{2}{*}{$\begin{array}{l}\mathbf{F} \\
0.2 \\
\end{array}$} & \multirow{2}{*}{$\begin{array}{l}\text { Sig. } \\
0.7 \\
\end{array}$} \\
\hline COP L/m & No Ex. SHS (16) & & & & \\
\hline & Ex. SHS (19) & $3.1-7.4$ & $5.3 \pm 1.3$ & & \\
\hline \multirow{2}{*}{$\begin{array}{ll}\text { RV mass } \\
\text { gm }\end{array}$} & Not Ex. SHS (16) & $3.7-6.4$ & $5.0 \pm 0.7$ & 0.03 & 0.9 \\
\hline & Ex. SHS (19) & $3.8-6.02$ & $5.1 \pm 0.6$ & & \\
\hline \multirow[t]{2}{*}{$\% \mathrm{FAC}$} & Not Ex. SHS (16) & $42-54$ & $47.9 \pm 0.03$ & 2.1 & 0.16 \\
\hline & Ex. SHS (19) & $43-60$ & $49.8 \pm 0.04$ & & \\
\hline \multirow[t]{2}{*}{$\mathrm{E} \mathrm{cm} / \mathrm{s}$} & No Ex. SHS (16) & $67.0-97.0$ & $82.9 \pm 9.5$ & 0.3 & 0.6 \\
\hline & Ex. SHS (19) & $68.0-93.0$ & $84.5 \pm 8.3$ & & \\
\hline \multirow[t]{2}{*}{ E/A } & Not Ex. SHS (16) & $1.2-2.1$ & $1.4 \pm 0.2$ & 2.4 & 0.1 \\
\hline & Ex. SHS (19) & $1.1-1.6$ & $1.3 \pm 0.13$ & & \\
\hline
\end{tabular}

Ex. SHS: exposure to second hand smoke. RV: right ventricle; $\mathrm{CO}$ : Cardiac Output; \%FAC: percent fractional area change; *P-value is significant at $\mathrm{P}<0.01$, ** highly significant.

Table (3): Two Dimensional and M-mode structural and functional dimensions of the right side of the heart in infants 3-12 months of age months exposed to passive smoking vs. those not exposed to smoke

\begin{tabular}{|c|c|c|c|c|c|c|}
\hline \multicolumn{2}{|c|}{$\begin{array}{l}\text { Variables and groups under study } \\
\text { (number of cases) }\end{array}$} & \multirow{2}{*}{$\begin{array}{l}\text { Range } \\
1.29-2.0 \\
\end{array}$} & \multirow{2}{*}{$\begin{array}{l}\text { Mean } \pm \\
\text { Deviation }\end{array}$} & & \multirow{2}{*}{$\begin{array}{l}\text { F-ratio } \\
2.420 \\
\end{array}$} & \multirow{2}{*}{$\begin{array}{l}\text { Sign. } \\
0.13 \\
\end{array}$} \\
\hline TAPSE $\mathrm{cm}$ & Not Ex. SHS (16) & & & & & \\
\hline & Ex. SHS (19) & $1.1-1.7$ & $1.5 \pm 0.17$ & & & \\
\hline \multirow[t]{2}{*}{ RVOT d cm } & Not Ex. SHS (16) & $1.1-1.5$ & $1.3 \pm 0.09$ & & .001 & 0.975 \\
\hline & Ex. SHS (19) & $1.0-1.4$ & $1.3 \pm 0.1$ & & & \\
\hline \multirow[t]{2}{*}{ RV VTI cm } & Not Ex. SHS (16) & $13.3-22.0$ & $16.9 \pm 2.3$ & & 0.11 & 0.7 \\
\hline & Ex. SHS (19) & $14.0-27.0$ & $17.2 \pm 3.08$ & & & \\
\hline \multirow[t]{2}{*}{ RVd cm } & Not Ex. SHS (16) & $1.1-1.4$ & $1.2 \pm 0.07$ & & 4.291 & 0.046 \\
\hline & Ex. SHS (19) & $1.2-1.5$ & $1.3 \pm 0.09$ & & & \\
\hline
\end{tabular}

Ex. SHS: exposure to second hand smoke. TAPSE: Tricuspid annular plane systolic excursion; RVOT d: right ventricular outflow tract diameter; RV VTI: right ventricular velocity time integral; RVd: right ventricular diameter. ${ }^{*} \mathrm{P}$-value is significant at $\mathrm{P}<0.01$, ** highly significant. 
Table (4) Tissue Doppler imaging to assess right ventricular diastolic and systolic function in formula fed infants aged 3-12 months exposed to passive smoking vs. those not exposed

\begin{tabular}{|c|c|c|c|c|c|}
\hline \multicolumn{2}{|c|}{$\begin{array}{l}\text { TDI for TV at septum and groups } \\
\text { under study (number of cases) }\end{array}$} & \multirow{2}{*}{$\begin{array}{l}\text { Range } \\
7.0-10.5 \\
\end{array}$} & \multirow{2}{*}{$\begin{array}{l}\text { Mean } \\
\text { Deviation }\end{array}$} & \multirow{2}{*}{$\begin{array}{l}\text { F-ratio } \\
.089 \\
\end{array}$} & \multirow{2}{*}{$\begin{array}{l}* \text { Sig. } \\
0.77\end{array}$} \\
\hline$S$ wave $\mathrm{cm}$ & Not Ex. SHS (16) & & & & \\
\hline & Ex. SHS (19) & $6.9-9.3$ & $8.1 \pm 0.7$ & & \\
\hline \multirow[t]{2}{*}{ E wave cm } & Not Ex. SHS (16) & $11.1-14.7$ & $12.5 \pm 0.96$ & 16.028 & $0.000 * *$ \\
\hline & Ex. SHS (19) & $8.60-12.80$ & $11.1 \pm 1.1$ & & \\
\hline \multirow[t]{2}{*}{ A wave cm } & Not Ex. SHS (16) & $6.30-11.5$ & $8.6 \pm 1.6$ & 1.458 & 0.24 \\
\hline & Ex. SHS (19) & $6.50-11.0$ & $8.0 \pm 1.2$ & & \\
\hline \multirow[t]{2}{*}{ ICT $\mathrm{m} / \mathrm{s}$} & Not Ex. SHS (16) & $30.0-34.0$ & $31.9 \pm 1.2$ & 2.050 & 0.16 \\
\hline & Ex. SHS (19) & $24.0-37.0$ & $33.0 \pm 2.9$ & & \\
\hline \multirow[t]{2}{*}{ IRT $\mathrm{m} / \mathrm{s}$} & Not Ex. SHS (16) & $31.0-36.0$ & $33.6 \pm 1.6$ & .024 & 0.9 \\
\hline & Ex. SHS (19) & $24.0-36.0$ & $33.7 \pm 2.8$ & & \\
\hline \multirow[t]{2}{*}{ E/E' prime } & Not Ex. SHS (16) & $5.0-8.2$ & $6.65 \pm 0.9$ & 10.536 & $0.003 * *$ \\
\hline & Ex. SHS (19) & $6.2-10.1$ & $7.7 \pm 0.9$ & & \\
\hline
\end{tabular}

Ex. SHS: exposure to passive smoking; ICT: isovolumetric contraction time, IRT: isovolumetric relaxation time;. E/E’: E wave to E prime ratio; *P-value is significant at $\mathrm{P}<0.01$, ** highly significant.

Table (5): Tissue Doppler imaging findings at lateral annular plane of tricuspid valve in infants aged 312 months exposed to passive smoking vs. not exposed to passive smoking among formula fed infants

\begin{tabular}{|l|l|l|l|l|l|}
\hline \multicolumn{2}{|c|}{$\begin{array}{l}\text { TDI at anterior leaflet of TV and } \\
\text { groups under study (number of cases) }\end{array}$} & Range & Mean \pm Std Dev. & F-ratio & $\begin{array}{l}\text { P-value } \\
\text { (Sig.) }\end{array}$ \\
\hline \multirow{2}{*}{ S wave cm } & Not Ex. SHS (16) & $8.2-13.2$ & $10.5 \pm 1.5$ & 0.07 & 0.9 \\
\cline { 2 - 6 } & Ex. SHS (19) & $7.6-13$ & $10.6 \pm 1.6$ & & \\
\hline \multirow{2}{*}{ E wave cm } & Not Ex. SHS (16) & $11.6-17.6$ & $13.75 \pm 1.8$ & 0.02 & 0.9 \\
\cline { 2 - 6 } & Ex. SHS (19) & $9.4-17.8$ & $13.7 \pm 1.75$ & & \\
\hline \multirow{2}{*}{ A wave cm } & Not Ex. SHS (16) & $7.5-15.4$ & $9.6 \pm 2.2$ & 0.01 & 0.9 \\
\cline { 2 - 6 } & Ex. SHS (19) & $7.0-13.9$ & $9.5 \pm 2.4$ & 2.6 & 0.1 \\
\hline \multirow{2}{*}{ ICT m/s } & Not Ex. SHS (16) & $30.0-36.0$ & $32.4 \pm 1.5$ & & \\
\cline { 2 - 6 } & Ex.SHS (19) & $31.0-37.0$ & $33.3 \pm 1.7$ & 0.45 & 0.51 \\
\hline \multirow{2}{*}{ IRT m/s } & No Ex.SHS (16) & $30.0-36.0$ & $34.0 \pm 1.6$ & & \\
\cline { 2 - 6 } & Ex. SHS (19) & $32.0-37.0$ & $34.4 \pm 1.6$ & & \\
\hline \multirow{2}{*}{ E/E' prime } & No Ex.SHS (16) & $5.11-8.4$ & $6.0 \pm 0.9$ & & \\
\cline { 2 - 6 } & Ex. SHS (19) & $3.8-9.5$ & $6.3 \pm 1.1$ & & \\
\hline
\end{tabular}

TDI: tissue Doppler imaging; Ex.SHS: exposure to passive smoking. RV: right ventricle; E: rapid early (passive) RV filling; E/E': E to E prime ratio; ICT: isovolumetric contraction time, IRT: isovolumetric relaxation time; *P-value is significant at $\mathrm{P}<0.01$, ** highly significant. 
Table (6) Correlative studies between exposure to passive smoking and echocardiography parameters of the right side of the hearts in infants aged 3-12 months who were formula fed from birth

\begin{tabular}{|l|l|l|l|l|l|l|l|l|}
\hline $\begin{array}{l}\text { Exposure to } \\
\text { SHS in FF (38) }\end{array}$ & $\begin{array}{l}\text { RV d } \\
\mathbf{c m}\end{array}$ & $\begin{array}{l}\text { RV } \\
\text { VTI_cm }\end{array}$ & $\begin{array}{l}\text { RVOT } \\
\mathbf{d ~ c m}\end{array}$ & $\begin{array}{l}\text { TAPSE } \\
\mathbf{c m}\end{array}$ & $\begin{array}{l}\text { S' } \\
\text { wave } \\
\mathbf{c m}\end{array}$ & $\begin{array}{l}\text { E' } \\
\text { wave } \\
\mathbf{c m}\end{array}$ & $\begin{array}{l}\text { A' } \\
\text { wave } \\
\mathbf{c m}\end{array}$ & $\begin{array}{l}\text { E/E' } \\
\text { ratio }\end{array}$ \\
\hline $\begin{array}{l}\text { Pearson } \\
\text { Correlation }\end{array}$ & $\mathrm{r} 0.34^{*}$ & $\mathrm{r} 0.06$ & $\mathrm{r}-0.01$ & $\mathrm{r}-0.05$ & $\mathrm{r}-0.6^{* *}$ & $\mathrm{r}-0.2$ & $\mathrm{r} 0.5^{* *}$ & $\mathrm{r}-0.3$ \\
\hline Sig. (2-tailed) & 0.046 & 0.743 & 0.975 & 0.8 & 0.000 & 0.24 & 0.003 & 0.13 \\
\hline
\end{tabular}

Ex.SHS: exposure to passive smoking, $\mathrm{FF}=$ formula fed. $\mathrm{RV}$ : right ventricle; $\mathrm{E}$ : rapid early (passive) $\mathrm{RV}$ filling; E/e': E wave to e prime ratio TAPSE: Tricuspid annular plane systolic excursion; RVOT d: right ventricular outinflow tract diameter; RV VTI: right ventricular velocity time integral; RVd: right ventricular diameter*Correlation is significant at the 0.05 level (2-tailed).** Correlation is significant at the 0.01 level (2-tailed).

Table (7): Correlative studies of exposure to passive smoking with echocardiography parameters of the right side of the hearts in infants aged 3-12 months who were exclusively breastfed from birth for at least 3 months

\begin{tabular}{|l|l|l|l|l|l|l|l|l|}
\hline $\begin{array}{l}\text { Exposure to } \\
\text { SHS (36) }\end{array}$ & $\begin{array}{l}\text { RV d } \\
\text { cm }\end{array}$ & $\begin{array}{l}\text { RV } \\
\text { VTI_cm }\end{array}$ & $\begin{array}{l}\text { RVOT d } \\
\text { cm }\end{array}$ & $\begin{array}{l}\text { TAPSE } \\
\text { cm }\end{array}$ & S wave & $\begin{array}{l}\text { E } \\
\text { wave }\end{array}$ & $\begin{array}{l}\text { A } \\
\text { wave }\end{array}$ & E/E' \\
\hline $\begin{array}{l}\text { Pearson } \\
\text { Correlation }\end{array}$ & $\mathrm{r}-0.1$ & $\mathrm{r} 0.1$ & $\mathrm{r} 0.25$ & $\mathrm{r}-0.2$ & $\mathrm{r}-0.1$ & $\mathrm{r}-0.2$ & $\mathrm{r}-0.2$ & $\mathrm{r}-0.2$ \\
\hline $\begin{array}{l}\text { Sig. } \\
\text { tailed) }\end{array}$ & 0.53 & 0.52 & 0.14 & 0.9 & 0.6 & 0.24 & 0.24 & 0.2 \\
\hline
\end{tabular}

Ex.SHS: exposure to passive smoking, EBF: exclusively breastfed . RV: right ventricle; E: rapid early (passive) RV filling; E/e': E wave to e prime ratio TAPSE: Tricuspid annular plane systolic excursion; RVOT d: right ventricular outflow tract diameter; RV VTI: right ventricular velocity time integral; RVd: right ventricular diameter.

*Correlation is significant at the 0.05 level (2-tailed).

\section{Discussion}

Overall, in this random sample of infants a higher proportion of infants were exposed to SHS, indicating the high prevalence of this condition as a public health problem to both parents and children. Infants suffer the most since they are exposed over a longer period, moreover, the first two years of their life are characterized by rapid growth and differentiation of their body tissues and organs and thereby make them at greater risk of damage placing them at risk of a life time of unknown consequences.

It was interesting to note that mothers who were working were less liable to have husbands who were smokers, although there was no significant difference in the age of the husband or educational status of parity in-between the groups exposed to SHS and those not exposed to SHS.

Echocardiography is a simple non-invasive technique that can assist us in understanding the pathophysiological changes that can happen to the cardiovascular structures and function of these young infants and children.

The study showed that $\mathrm{CO} ; \% \mathrm{FAC}$ and RV mass, were not significantly different between those infants not exposed to SHS and those exposed to SHS. Right sided CO in infants is usually less than CO on left side, but progressively rises as more pulmonary tissue open up and resistance decreases in pulmonary bed. The absence of any difference in relation to SHS probably indicates that CO was not influenced by SHS. CO is represented by stroke volume multiplied by heart rate, which again could be inaccurate with babies who are crying. Also another estimate is to VTI multiplied by the CSA or RVOT multiplied by heart rate. Cardiac 
index is derived from CO divided by body surface area (BSA). Normal values of CO is $150-400 \mathrm{ml} / \mathrm{kg} / \mathrm{day}$ (Ishii et al, 2000).

Percent FAC is the difference between right ventricular end diastolic area (RVEDA) and end systolic area (RVESA) divided by RVEDA multiplied by 100 . The normal values are $43 \pm 18 \%$ and less than $35 \%$ is considered systolic dysfunction. However unlike the left ventricle where $\%$ FAC is a reliable index of systolic function, in the RV, \%FAC is not areliable measure of systolic function and echocardiographer rely more on eye balling the RV. More reliable echo measurements of systolic function are TAPSE and tissue Doppler imaging of the S' wave which represents peak systolic right ventricular filling. Ilgenli et al (2007) reported no effect of SHS on RV systolic function but reported that diastolic function was impaired probably due to progressive increase in pulmonary artery pressure.

The main findings of evidence of diastolic dysfunction (DD) in FF came from TDI which showed a significant decrease in $\mathrm{E}$ wave (passive filling of RV) and significant increase in the E/E' $>7$ in FF infants exposed to SHS vs. those not exposed to SHS. The cutoff for children is not clear for DD but in adults a cut off of 7 is used to indicate DD. This indicates a potential risk for these infants to develop DD (Tissot et al., 2018).

Moreover there was a highly significant negative correlation observed between SHS status and S' (r0.6) and a significant positive correlation with $\mathrm{A}^{\prime}$ wave ( $\left.\mathrm{r} 0.5\right)$. S' wave represents peak systolic annular velocity and its decrease to $<10 \mathrm{~cm} / \mathrm{sec}$ is an indicator of global right ventricular systolic dysfunction, while the E' and A' waves on TDI allows the estimation of diastolic function. TDI is the most reliable and accurate technique to assess diastolic function in children (Tissot et al., 2018).

The E wave which represent early passive ventricular filling. It may be either reversed or exaggerated or increased in either mild or severe DD. The E wave is preload dependent. In children the increase in E/E' signifies decreased or disordered diastolic function. SHS with increased E/E' reflects increased stress on diastolic function.

Several research teams have looked at echocardiographic parameters in adults exposed to SHS and found no effect on systolic function. The main impairment was in diastolic function through increased after load due to increased pulmonary artery pressure (Ilgenti et al., 2007). A study that examined effects of smoking on left and right ventricular relaxation in young healthy smokers found impaired relaxation of LV and RV diastolic dysfunction especially in those with coronary heart disease (Lichodzeiejewska et al., 2007). The underlying mechanism was suggested to due to the increase in carboxyhemoglobin levels, since smoke is rich in carbon monoxide (Dogan et al., 2011). This can be deleterious to the growing and differentiating tissues of the young infants, which impairs oxygenation and thereby suffocates the developing tissues, especially the brain and immune system. Other studies have shown that breastfed vs. formula fed by bottle had higher oxygen saturations after a feed and this improved when babies both breastfed or formula fed where held in skin to skin contact after the feed (Abdelwahed et al., 2012).

The mechanism for DD in FF infants could be attributed to the mode of feeding which does not involve active suckling at the breast which results in higher oxygen saturation when they are directly at the breast. Episode or apnea and oxygen desaturation are common with bottle feeding and absent with breastfeeding (Chen et al., 2000). Hence FF is more stressful in infants and this can explain the DD which is increased with SHS versus the breastfed group of infants who showed no impairment in their diastolic function in this study. Also FF infants usually overfeed and this bolus feeding interferes with the rise in the oxygen saturation (Kuik et al., 2019). The absence of a mechanism for satiety in FF vs breastfed who have better control their intake (DiSantis et al., 2011) may play an role in increasing the pulmonary resistance and pressure on the lungs and decreasing the heart rate in FF infants. Moreover the gastric emptying time is much shorter in breastfed this allows the stomach to exert less pressure on the pulmonary bed allowing easier expansion of the lungs and decrease in pulmonary resistance and thereby improved blood flow. The components in human milk influence infant feeding patterns and gastric emptying through appetite hormones as Leptin and Adiponectin, which were shown to be high in human milk and have a significant role in control of appetite. Other macronutrients also regulate gastric emptying time (Grineva et al., 2017). 
A study by conducted for breastfed infants exposed to second hand smoke showed that these infants had higher level of cotinine in their urine, indicating increased capacity to excrete these harmful products unlike FF who had less capacity to do that. Breastfeeding seems to have a diuretic effect that enhances body of the infant to rid itself of harmful chemical to which child is exposed (Mostafa et al., 2012)

In conclusion, Formula milk fed infants who are bottle fed and are exposed to second hand smoke have a higher potential to risk of diastolic dysfunction, On the other hand breastfeeding seems to exert a protective effect for infants exposed to SHS. The mechanism underlying this is complex and involves many underlying factors as oxygenation, gastric emptying, appetite control and carboxyhemoglobin i.e. components in tobacco and components in breastmilk which are absent in formula milk. Practices such as exclusive breastfeeding, and avoidance of bottles and FF, practice of skin-to-skin care and increasing the intensity of breastfeeding, can be beneficial in improving diastolic function in infants exposed to SHS (Abed et al., 2013).

\section{References}

[1.] Abdelwahed M., Abul-Fadl AMAM., Lotfy WMN., AlTaweel AAR. Skin-to-skin care for managing congestive heart failure in infants with congenital heart disease. MCFC-Eg J Breastfeeding (EJB). 2012;4:59-69. (www.mcfcare.org/publication/)

[2.] Abed NT., Waked N., Abul-Fadl AM., ElHady H, Mostafa ME. An intervention to reduce exposure of neonates to environmental tobacco smoke by exclusive breastfeeding. MCFCEgyptian J Breastfeeding. 2013; Jan. 7:29-40.

[3.] Behairy OA., Abul-Fadl AM, Arafa OS, Abuol-Fadl A, Attia MA. Influence of early feeding practices on biomarkers of cardiovascular disease risk in later life. Gaz Eg Ped Ass. 2017; 65:114121.

[4.] Chen CH., Wang TM., Chang HM., Chi CS. The effect of breast- And Bottle feeding on oxygen saturation and body temperature in preterm infants. J Hum Lact. 2000; 16(1):21-7.

[5.] de Jonge LL, van Osch-Gevers L, et al. Breastfeeding is not associated with left cardiac structures and blood pressure during the first two years of life: the Generation R Study. Early Hum Dev. 2010;86:463-8.

[6.] DiSantis KI., Collins BN., Fisher JO., Davey A. Do infants fed directly from the breast have improved appetite regulation and slower growth during early childhood compared with infants fed from a bottle? Int J Behav Nutr Phys Act. 2011;8-89.

[7.] Dogan A, Yarlioglues M., Gul I., Kaya MG., Ozdogru I., Kalay N., et al. Acute effects of passive smoking on left ventricular systolic and diastolic function in healthy volunteers. J Am Soc Echocardiogr. 2011; 24(2):185-91.

[8.] Uysal F, Bostan ÖM, et al, Determination of reference values for tricuspid annular plane systolic excursion in healthy Turkish children Anatol J Cardiol. 2016 May; 16(5): 354-359.Published online 2015 May 5. doi: 10.5152/akd.2015.6227

[9.] Gridneva Z., Kugananthan S., Hepworth AR., Tie WJ., Lai CT., Ward LC., Hartmann PE., Geddes D. Effect of human milk appetite hormones, macronutrients and infant characteristics on gastric emptying and breastfeeding patterns of term fully breastfed infants. Nutrients. 2017. 9(1): 15 .

[10.] Ilgenli TF., Akpinar O. Acute effects of smoking on right ventricular function A tissue Doppler imaging study on healthy adults. Swiss Med Wkly. 2007; 137(5-6):91-96.

[11.] Koestenberger M, Ravekes W, et al. Reference values of the right ventricular outflow tract systolic excursion in 711 healthy children and calculation of z-score values. Eur Heart J Cardiovasc Imaging. 2014 Sep; 15(9):980-6.

[12.] Kuik SJ., van Zoonen AGJF., Bos AF., Kooi EMW. The effect of enteral bolus feeding on regional intestinal oxygen saturation in preterm infants is age dependent: a longitudinal observational study.BMC Pediatrics. 2019. 19(404).

[13.] Lichodziejewska B. et al. Chronic and acute effects of smoking on left and right ventricular relaxation in young healthy smoker. Chest. 2007; 131(4):1142-1148. 
[14.] Martin RM, Ebrahim S, et al. Breastfeeding and atherosclerosis: intima-media thickness and plaques at 65-year follow-up of the Boyd Orr cohort. Arterioscler Thromb Vasc Biol. 2005; 25:1482-8.

[15.] Martin RM, Ness AR, et al. Does breastfeeding in infancy lower blood pressure in childhood? The Avon longitudinal study of parents and children (ALSPAC). Circulation. 2004; 109:1259-1266.

[16.] Metsios GS., Flouris AD., Angioi M., Kouteddakis Y. Passive smoking and the development of cardiovascular disease in children: A systemic review. Cardiol Res Pract. 2011, 2011:587650.

[17.] Miller MD., Broadwin R., Green S., et al. Health effects assessment for environmental Tobacco smoke. Sacremento, Calif, USA: California Environmental Protection Agency; 2005.

[18.] Mostafa ME. Impact of breastfeeding Interventions for reducing the effects of passive smoking in infants. Master thesis in Pediatrics. Supervised by Azza AM Abul-Fadl, Hala ME Hashim, Nevine T Abed, Nevin Waked. Benha Faculty of Medicine, Benha University, Egypt. 2012.

[19.] Ong KK, Preece MA, et al. Size at birth and early childhood growth in relation to maternal smoking, parity and infant breastfeeding: longitudinal birth cohort study and analysis. Pediatr Res 2002;52(6): 8637.

[20.] Owen CG, Whincup PH, K, et al. Does initial breastfeeding lead to lower blood cholesterol in adult life? A quantitative review of the evidence. Am J Clin Nutr. 2008;88:305-14.

[21.] Rushton L. Health impact of environmental tobacco smoke in the home. Reviews on Environmental Health. 2004; 19(3-4):291-309.

[22.] Tissot C, Sigh Y, Sekars KN. Echocardiographic evaluation of ventricular function for neonatologist and pediatric intensivist. Front Pediatr. 2018; 04 April, https://doi.org/10.3389/fped.2018.00079. 